\title{
Microstructure, Residual Strain and Stress Corrosion Cracking Behavior in 316L Heat-Affected Zone
}

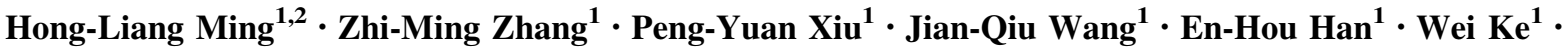 \\ Ming-Xing $\mathrm{Su}^{3}$
}

Received: 23 March 2016/Revised: 7 June 2016/Published online: 5 July 2016

(c) The Chinese Society for Metals and Springer-Verlag Berlin Heidelberg 2016

\begin{abstract}
Austenitic stainless steels are usually chosen to make many components of nuclear power plants (NPPs). However, their microstructure in the heat-affected zone (HAZ) will change during the welding process. Some failures of the weld joints, mainly stress corrosion cracking (SCC), have been found to be located in the HAZ. In this research, the microstructure, micro-hardness, residual strain and SCC behavior at different locations of the 316L HAZ cut from a safeend dissimilar metal weld joint were studied. However, traditional optical microscope observation could not find any microstructural difference between the HAZ and the base metal, higher residual strain and micro-hardness, and higher fraction of random high-angle grain boundaries were found in the HAZ than in the base metal when studied by using electron back-scattering diffraction scanning and micro-hardness test. What's more, the residual strain, the microhardness and the fraction of random grain boundaries decreased, while the fraction of coincidence site lattice grain boundaries increased with increasing the distance from the fusion boundary in 316L HAZ. Creviced bent beam test was applied to evaluate the SCC susceptibility at different locations of 316L HAZ and base metal. It was found that the HAZ had higher SCC susceptibility than the base metal and SCC resistance increased when increasing the distance from the fusion boundary in 316L HAZ.
\end{abstract}

KEY WORDS: Austenitic stainless steels; Heat-affected zone; Microstructure; EBSD; Residual strain; Stress corrosion cracking

Available online at http://link.springer.com/journal/40195

Jian-Qiu Wang

wangjianqiu@imr.ac.cn

1 Key Laboratory of Nuclear Materials and Safety Assessment, Liaoning Key Laboratory for Safety and Assessment Technique of Nuclear Materials, Institute of Metal Research, Chinese Academy of Sciences, Shenyang 110016, China

2 University of Chinese Academy of Sciences, Beijing 100049, China

3 Shanghai Research Center for Weld and Detection Engineering Technique of Nuclear Equipment, Shanghai 201306, China

\section{Introduction}

Austenitic stainless steels are usually chosen to fabricate primary pipes of NPPs because of their proper strength and excellent corrosion resistance. However, low alloy steels are usually selected to make the pressure vessels not only due to their high strength but also due to their low cost $[1,2]$. And hence welding process is commonly used to connect these two parts. It has been well known that thermal cycles from the welding process, especially from the multi-pass welding process, can lead to high residual stress/strain and changes of the microstructure and properties in the HAZ of austenitic stainless steels, such as the change of the grain boundary type, higher micro-hardness, the formation of carbides and chromium-depleted zones adjacent to grain boundaries [1-4]. These special microstructures will affect the SCC 
resistance of the HAZ. In fact, it has been found that many failures of the weld joints, mainly SCC, are located at the HAZ [5]. By using slow strain rate test (SSRT) to evaluate the SCC susceptibility at distinct regions of a safe-end dissimilar metal weld joint (SA508-52M-316LN) in simulated primary water, the $316 \mathrm{LN} \mathrm{HAZ}$ was verified to have the highest SCC susceptibility [6].

Since SCC in the HAZ is a crucial problem and it is very important for the safe operation of the NPPs during the desired life time (40 or 60 or even 80 years), many researches concerning the SCC behavior in HAZ of austenitic stainless steel have been published [7-11]. Strain hardening and the resultant uneven distribution of deformation contribute to the enhanced SCC growth behavior in $316 \mathrm{~L} \mathrm{HAZ} \mathrm{in} \mathrm{high-temperature} \mathrm{pure} \mathrm{water} \mathrm{at} 288^{\circ} \mathrm{C}$ [7]. The microstructure, local deformation and microchemistry in Alloy $600 \mathrm{HAZ}$ and its SCC behavior in high-temperature water were studied by $\mathrm{Lu}$ et al. [8], and extensive intergranular stress corrosion cracking (IGSCC) was found in the HAZ. By using SSRT, Schvartzman et al. [11] found the HAZ of $316 \mathrm{~L}$ was susceptible to SCC when exposed to an environment similar to that of the primary circuit of pressurized water reactors (PWRs).

Actually, the SCC behavior of the HAZ is ascribed to the special microstructure formed during the welding process. Though some publications have demonstrated the high SCC sensitivity of the HAZ and even the SCC crack growth rate in the HAZ of some austenitic materials has been measured, the knowledge of the relationship between the microstructure and the SCC behavior at different locations in the HAZ is still not enough. In the present research, the microstructure, residual strain and SCC behavior of 316L HAZ cut from a safe-end dissimilar metal weld joint were studied to explore the relationship between the microstructure and SCC behavior in HAZ.

\section{Experimental}

\subsection{Introduction of the Dissimilar Metal Weld Joint}

The base metals were SA508-III low alloy steel and 316L stainless steel. ER309L and ER308L were chosen as the buttering metal and weld metal, respectively. The SA508III base metal was pre-heated before a buttering layer of 309L was deposited on the single- $\mathrm{V}$ groove of it by shielded metal arc welding (SMAW). Then postweld heat treatment was applied on the buttering layer to relieve the residual stress. After that, multi-pass and multi-layer (approximately 36 layers) welding was carried out between the buttering layer and the austenitic safe-end using SMAW and 308L electrodes, without any subsequent heat treatment. The detailed microstructure characterization and oxidation behavior in simulated primary water of different parts of this weld joint have been published $[2,12,13]$. The chemical compositions of the base metals, the buttering metal and the weld metal are given in Table 1 . The schematic diagram of the cross section of this dissimilar metal weld joint is shown in Fig. 1.

\subsection{Introduction of the CBB Test}

In order to evaluate the SCC behavior of different locations in 316L HAZ, CBB test was chosen for the SCC experiment since the thickness of the $\mathrm{CBB}$ sample could be small. What's more, very low tensile strain would be applied at the outer surface of the CBB sample which would have very limited effects on the original microstructure of 316L HAZ. Researches concerning CBB test used for studying SCC behavior have been published $[14,15]$. To avoid galvanic corrosion between the CBB samples and the clamps, the clamps were also fabricated by 316L. The schematic diagram of the clamps is shown in Fig. 2, and two CBB samples could be strained by one set of the clamps at the same time (Fig. 3).

The schematic diagram of the one notched CBB sample with the size of $30 \mathrm{~mm} \times 7.2 \mathrm{~mm} \times 2 \mathrm{~mm}$ is shown in Fig. 4. Four samples for the CBB test were cut from the 316L HAZ and base metal by electrical discharge machining, as shown in Fig. 1. The samples, named A, B, $\mathrm{C}$ and $\mathrm{D}$, were $0 \mathrm{~mm}, 2 \mathrm{~mm}, 4 \mathrm{~mm}$ and $\sim 30 \mathrm{~mm}$ away from the fusion boundary, respectively. All the notches with the identical depth of $0.625 \mathrm{~mm}$ were cut on the side which was close to the fusion boundary.

The CBB test was performed in 3\% (by weight) $\mathrm{NaOH}$ solution in a static autoclave with a pure nickel lining at $325{ }^{\circ} \mathrm{C}$ for $378.5 \mathrm{~h}$. Though the weld joint was served in the primary water environment, $\mathrm{NaOH}$ solution was used here to accelerate the SCC initiation and propagation process.

\subsection{Microstructure Observation and Micro- Hardness Test}

The samples of $316 \mathrm{~L}$ base metal and 316L HAZ for microstructure characterization were also cut from the same weld joint by electrical discharge machining. Then, the samples were ground by silicon carbide $(\mathrm{SiC})$ abrasive paper with grit sizes from 150 to 2000, followed by a final mechanical polishing with $2.5-\mu \mathrm{m}$ polishing paste. The samples were firstly electro-etched in $10 \%$ (by weight) oxalic acid $+90 \%$ (by weight) $\mathrm{H}_{2} \mathrm{O}$ solution and then in $10 \%$ (by weight) $\mathrm{KOH}+90 \%$ (by weight) $\mathrm{H}_{2} \mathrm{O}$ solution. Then, the metallurgical structures of these samples were observed with optical microscope (OM). 
Table 1 Chemical composition of materials in DMWJ (wt\%)

\begin{tabular}{lllllllllllll}
\hline Material & $\mathrm{C}$ & $\mathrm{Si}$ & $\mathrm{Mn}$ & $\mathrm{Cr}$ & $\mathrm{Ni}$ & $\mathrm{S}$ & $\mathrm{P}$ & $\mathrm{Fe}$ & $\mathrm{Mo}$ & $\mathrm{Cu}$ & $\mathrm{Al}$ & $\mathrm{Nb}$ \\
\hline 316L & 0.025 & 0.31 & 1.47 & 17.89 & 11.83 & 0.003 & 0.019 & Bal. & 2.47 & - & - & - \\
308L & 0.011 & 0.34 & 1.69 & 19.74 & 9.96 & 0.010 & 0.016 & Bal. & - & - & - \\
309L & 0.011 & 0.3 & 1.8 & 23.35 & 13.36 & 0.001 & 0.011 & Bal. & - & - & - & 0.01 \\
SA508 & 0.20 & 0.20 & 1.46 & 0.13 & 0.73 & 0.003 & 0.009 & Bal. & 0.50 & $<0.02$ & $<0.02$ & - \\
\hline
\end{tabular}

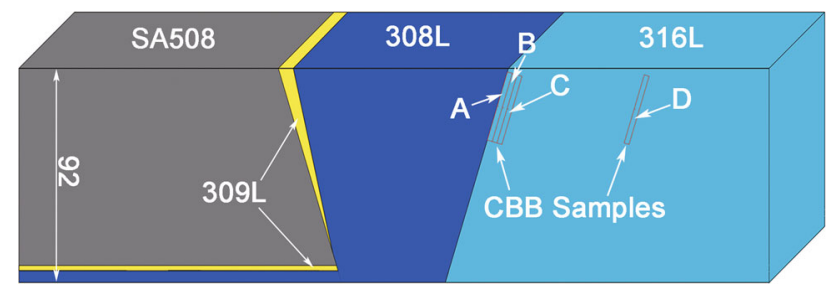

Fig. 1 Schematic illustration of the dissimilar metal weld joint and the positions of the CBB samples, marked by $A, B, C$ and $D$
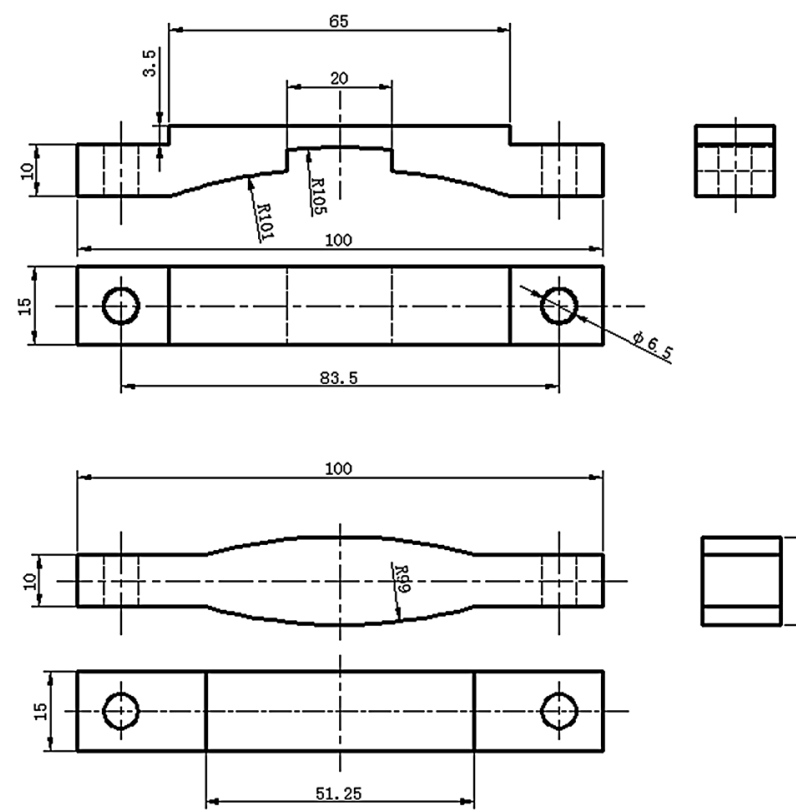

Fig. 2 Schematic diagram of the clamps used for CBB test

The grain boundary types and the residual strain distribution of the cross section of every CBB sample were studied by scanning electron microscopy (SEM, FEI XL30) equipped with a camera for EBSD scanning. The EBSD scanning voltage was $14 \mathrm{kV}$, with a scanning step size of $3.5 \mu \mathrm{m}$. Orientation imaging microscopy (OIM) software was used for EBSD data processing. The cross-sectional surface morphologies and the fractograph of the four CBB samples after immersion test were also studied by the same SEM. The micro-hardness was measured with an MHVD-

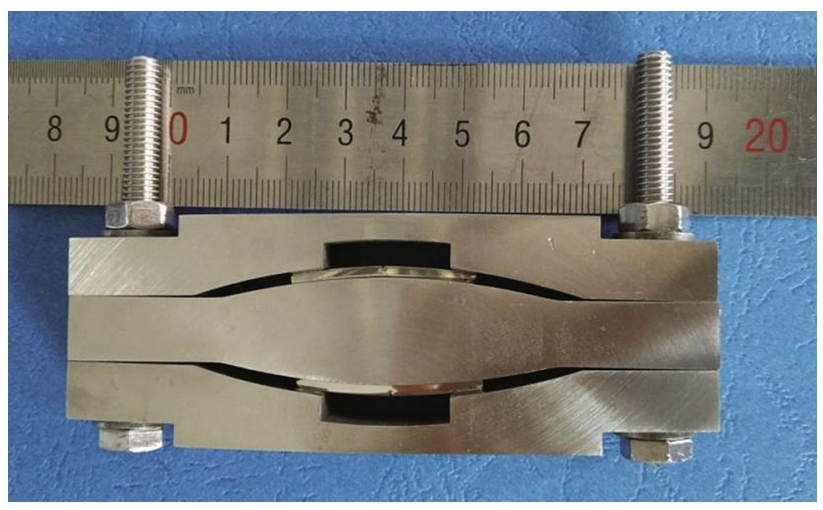

Fig. 3 Photograph of the sample and clamp assembly

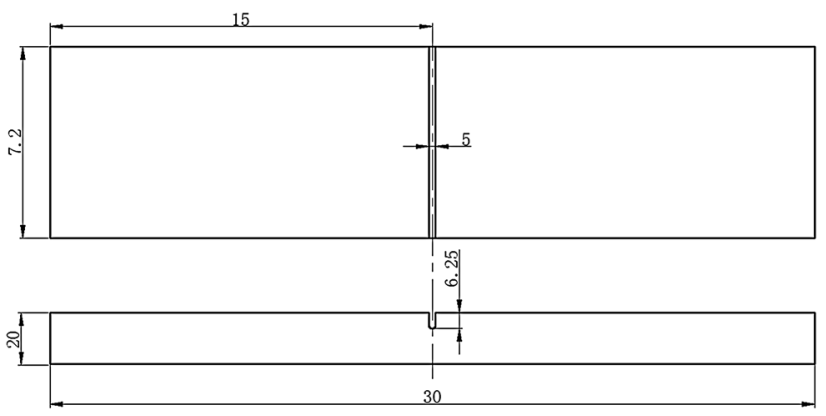

Fig. 4 Schematic diagram of the CBB sample

1000AP micro-hardness tester with a load of $4.9 \mathrm{~N}$ and a holding time of $15 \mathrm{~s}$.

\section{Results}

\subsection{OM Microstructure and Micro-Hardness of 316L Base Metal and HAZ}

The microstructure of 316L stainless steel base metal is illustrated in Fig. 5. Fine equiaxed grains with some annealing twins are found in the austenitic matrix. In addition, a small amount of delta ferrite in a form of stringers and dotted inclusions are randomly distributed within the grains and along the grain boundaries. 


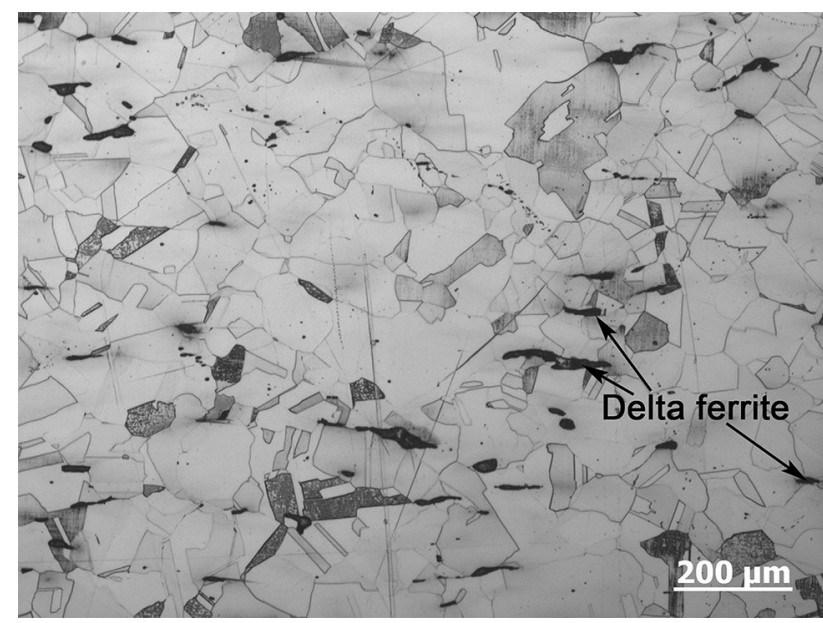

Fig. 5 Optical microstructure of $316 \mathrm{~L}$ base metal

A side view of the $316 \mathrm{~L}$ microstructure is shown in Fig. 6, and no significant HAZ is found in the $316 \mathrm{~L}$ stainless steel since the grain size in HAZ near the fusion boundary is similar to that of the base metal. Although the $316 \mathrm{~L}$ base metal near the fusion boundary experienced the welding thermal cycle, the grain growth trend is not obvious because of fast heating, short residence time under high temperature and rapid cooling. As a result, no coarsegrain zone is found near the fusion boundary [2].

The micro-hardness of 316L HAZ and base metal is shown in Fig. 7. HAZ has higher micro-hardness than the base metal. In detail, the average micro-hardnesses of samples A, B, C and D are $225 \mathrm{HV}_{0.5}, 215 \mathrm{HV}_{0.5}, 200 \mathrm{HV}_{0.5}$ and $180 \mathrm{HV}_{0.5}$, respectively.

\subsection{EBSD Scanning of 316L Base Metal and HAZ}

Though no obvious change can be found by optical microscope, the microstructural differences between the 316L base metal and HAZ can be observed by the EBSD test. Here, kernel average misorientation (KAM) is used to estimate the residual strain following a rainbow color code, with colors from blue to red denoting minimal to maximal residual strain. The observed boundaries were classified into three groups according to the coincidence site lattice (CSL) model: low-angle boundaries $\left(\mathrm{LAB}, 5^{\circ}<\theta<15^{\circ}\right.$ ), CSL boundaries $(3 \leq \Sigma \leq 29)$ and random high-angle grain boundaries $\left(\mathrm{RGB}, 15^{\circ}<\theta<180^{\circ}\right.$ ) [16]. The CSL designation was defined based on Palumbo-Aust's

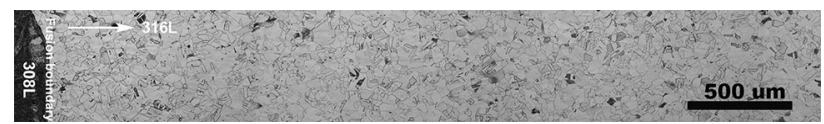

Fig. 6 Side-view optical microstructure of $316 \mathrm{~L}$ (from fusion boundary to base metal)

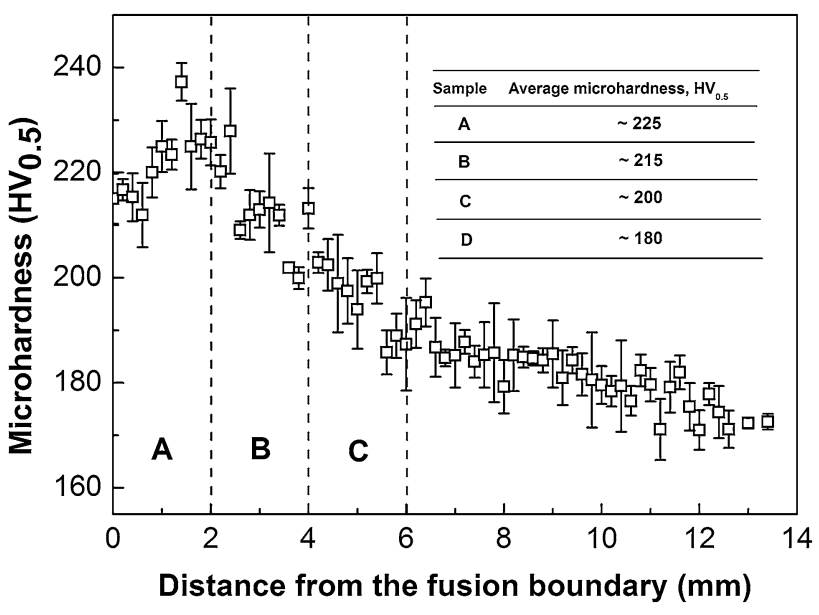

Fig. 7 Micro-hardnesses of the 316L HAZ and base metal

criterion [17], with the maximum allowable deviation angle obtained from the exact coincidence relationship, $\theta=15^{\circ} \Sigma^{-5 / 6} . \Sigma$ is the reciprocal density of coincident sites at the GB between two adjoining grains.

Figure $8 \mathrm{a}-\mathrm{d}$ is the cross-sectional EBSD scanning results of samples A-D before bending. From the inverse pole figures (IPFs) shown in Fig. 8a1-d1, no obvious grain-size change and no texture can be found as the orientations of the grains are randomly distributed. For KAM distribution maps, Fig. 8a2-c2, the residual strain decreases gradually with increasing the distance from the fusion boundary, that is, $\mathrm{KAM}_{\mathrm{A}}>\mathrm{KAM}_{\mathrm{B}}>\mathrm{KAM}_{\mathrm{C}}$. However, the residual strain of the base metal is a little higher than that of sample C. This may be caused by the non-uniformity of residual strain distribution in the base metal, and this phenomenon was also found in Ref. [2]. The grain boundary character distribution (GBCD) maps are shown in Fig. 8a3-d3, and light green, blue and red lines are represented as LAB, RGB and CSL boundaries, respectively.

Figures $9 \mathrm{a}-\mathrm{d}$ is the cross-sectional EBSD scanning results of samples A-D after bending. The changes of IPF, KAM and GBCD are very like these before bending. To evaluate the effects of the bending process on the microstructure change, the GBCD and KAM values of samples A-D before and after bending are summarized in Figs. 10 and 11, respectively. For both the original and the strained samples, increasing the distance from the fusion boundary, the proportion of LAB changes a little, while the proportion of CSL boundaries increases and the fraction of RGB decreases (Fig. 10). What's more, after the samples were strained by the CBB test clamps, the GBCD nearly has no change. However, as shown in Fig. 11, the residual strain of samples A-C increases. Interestingly, the residual strain of the base metal decreases after bending. The newly applied strain may be against the original one, and as a 


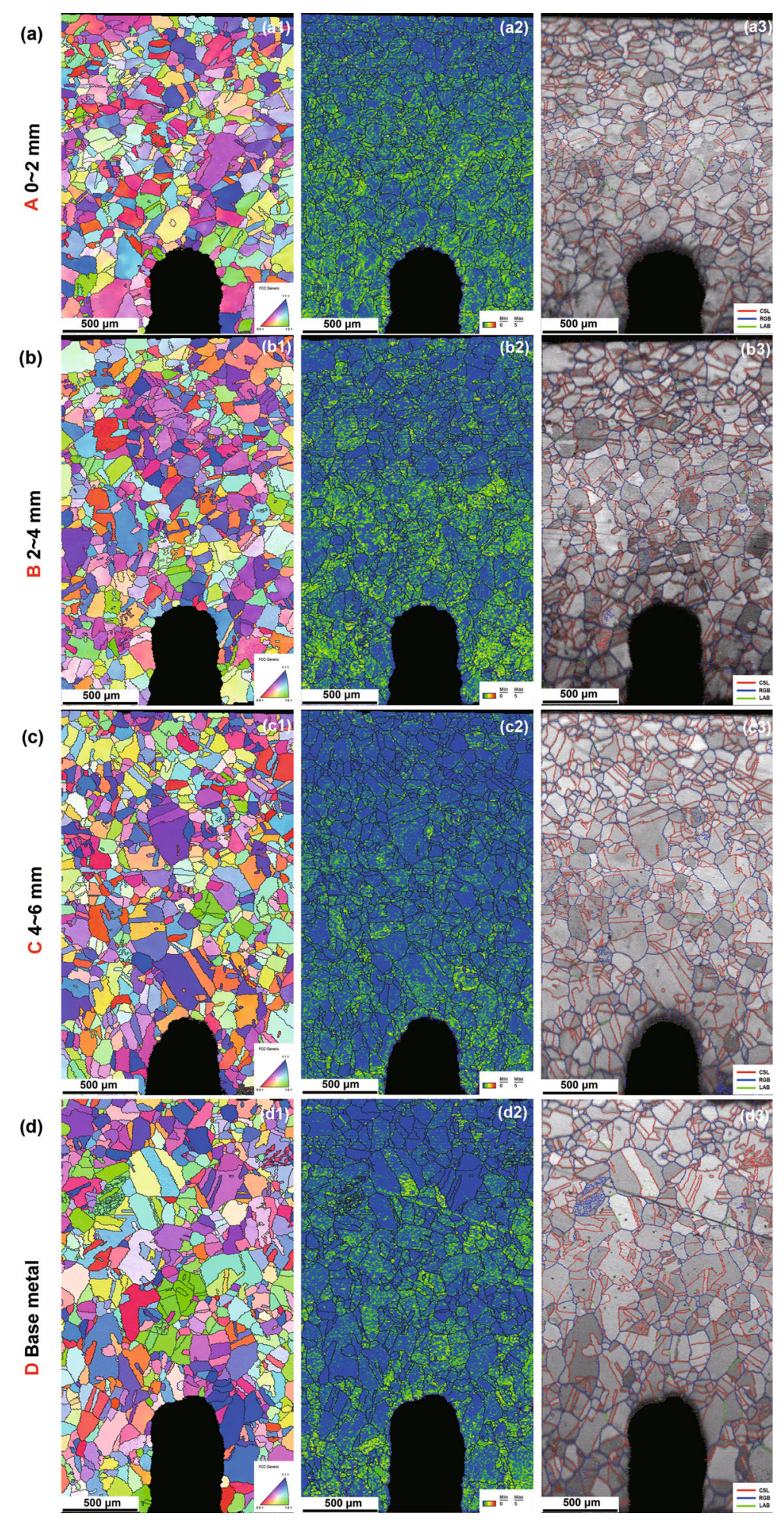

Fig. 8 a-d EBSD scanning results of the cross sections of samples A-D before bending. (a1)-(d1) Inverse pole figures, $(a 2)-(d 2)$ kernel average misorientation figures, $(a 3)-(d 3)$ grain boundary character maps

result, the strain in sample D decreases after bending. The bending of the samples by clamp does not change the microstructure severely, and as mentioned before, this is the reason why CBB test is chosen for the SCC experiment.

\subsection{SCC Behavior of 316L HAZ and Base Metal}

The surface morphologies of the four CBB samples after immersion in the $3 \%$ (by weight) $\mathrm{NaOH}$ solution at $325{ }^{\circ} \mathrm{C}$ 

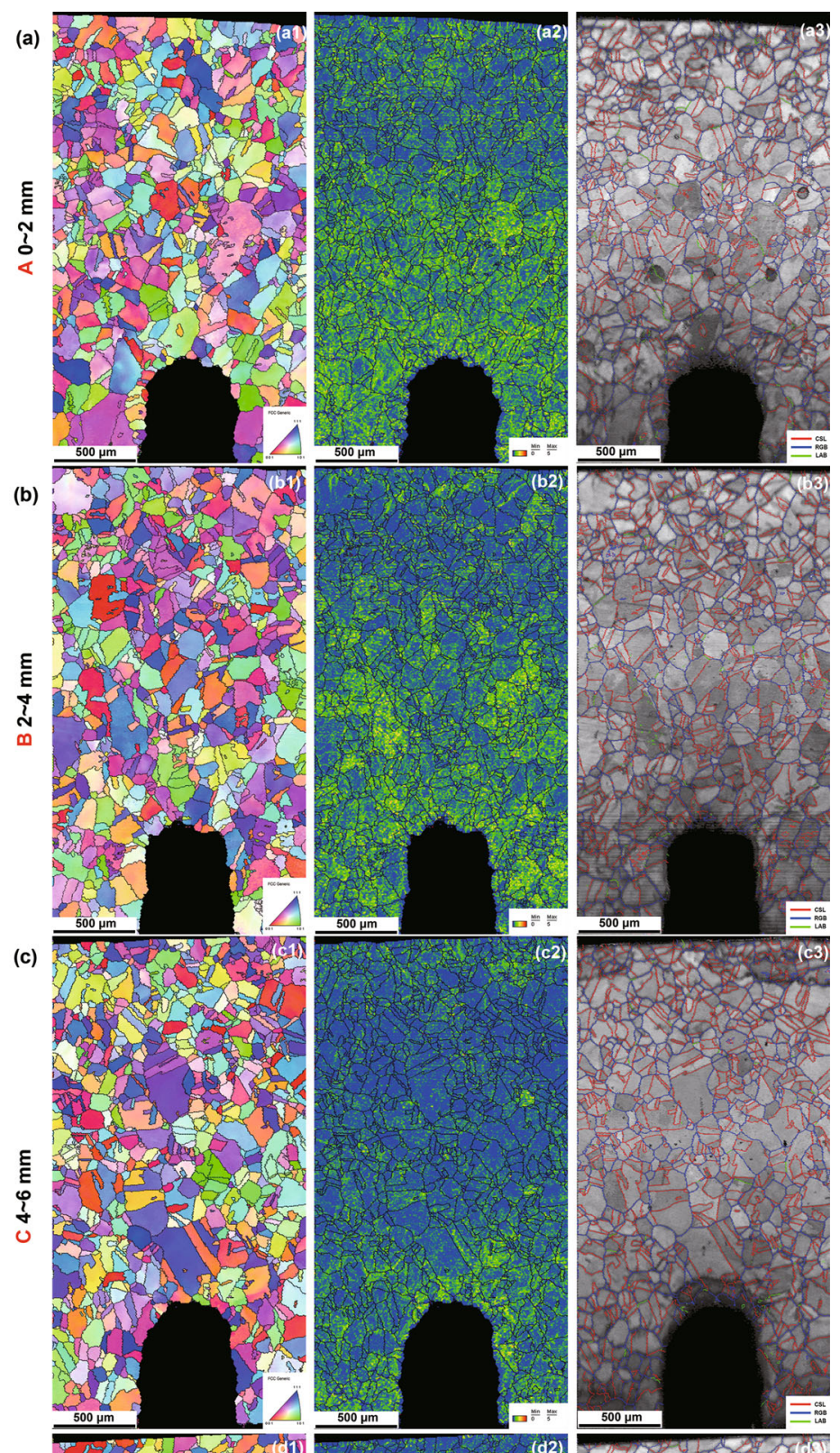

(d)
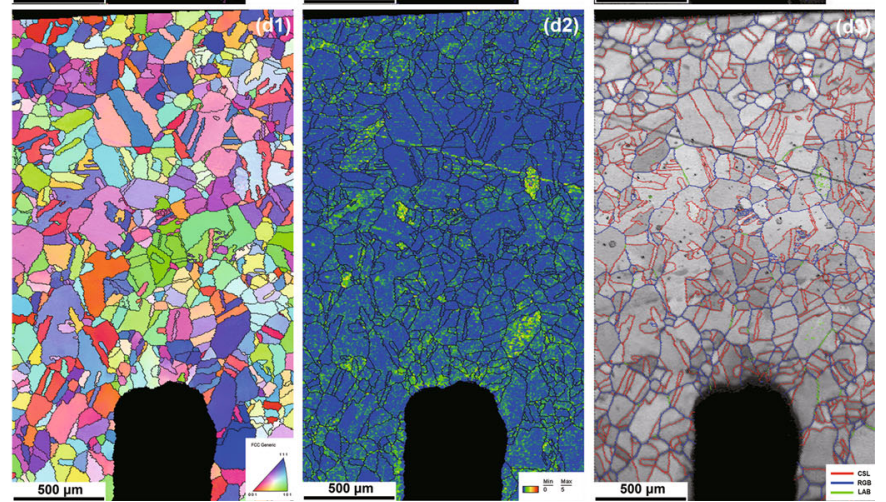

Fig. 9 a-d EBSD scanning results of the cross sections of samples A-D after bending. $(a 1)-(d 1)$ Inverse pole figures, $(a 2)-(d 2)$ kernel average misorientation figures, $(a 3)-(d 3)$ grain boundary character maps 

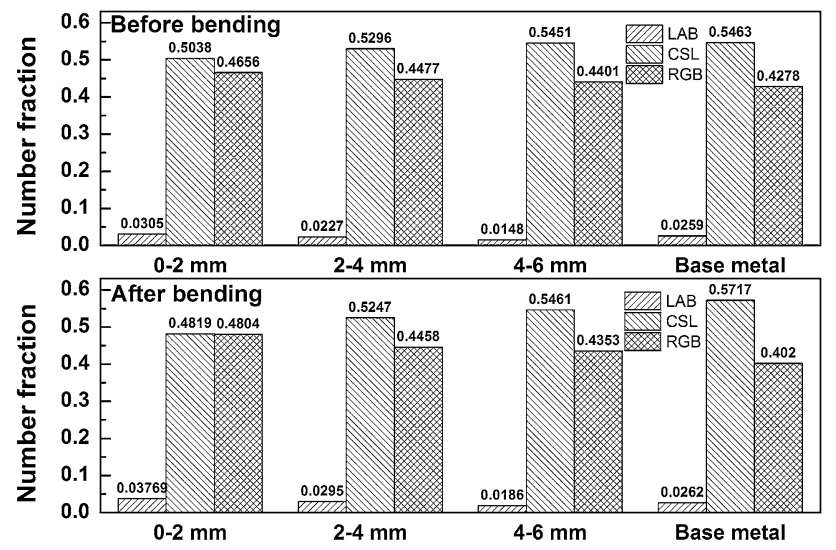

Fig. 10 Grain boundary character distribution of samples A-D before and after bending

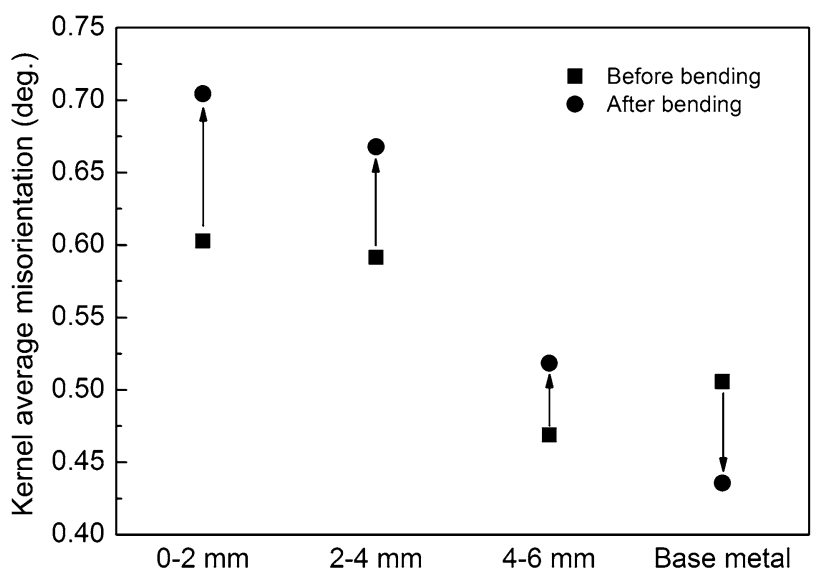

Fig. 11 Kernel average misorientation values of samples A-D before and after bending

for $378.5 \mathrm{~h}$ are shown in Fig. 12. It can be seen that SCC occurred on all samples. Moreover, the length and width of the cracks in the $316 \mathrm{~L} \mathrm{HAZ}$ are much larger than those in the base metal. By comparison, sample A which is the nearest one to the fusion boundary has the widest crack and has crack branches (or secondary cracks). Sample B has the longest main crack (about $1275 \mu \mathrm{m}$ ) among the four tested samples, and sample $\mathrm{C}$ has the shortest (about $300 \mu \mathrm{m}$ ) and narrowest crack among the three samples in HAZ. Meanwhile, more oxides can be observed on the outer surfaces of samples B and D than samples A and C. This should be caused by the fact that these two surfaces are placed upward in the solution, which is much easier for the oxides deposition.

However, the measured crack length on the outer surface cannot exactly reveal the SCC sensitivity of these four samples as the crack propagation may change in the thickness direction. Then, all of the four CBB samples were manually fractured in the liquid nitrogen. Figure 13a- d shows the SEM fractograph of the four CBB samples. The SCC areas are denoted between the orange and the white dash lines (Fig. 13a1-d1). From sample A to sample $\mathrm{D}$, the fraction of the SCC area to the total fracture surface decreases gradually, $91.67 \%$ (A) $>83.33 \%$ (B) $>64.25 \%$ (C) $>46.15 \%$ (D). As a result, it can be summarized that for the tested four samples, the closer to the fusion boundary, the lower the SCC resistance. Figure 13a2-d2 shows the local magnification of the SCC zones of the four samples, for detailed observation. Most of the crack propagation areas exhibit the characteristics of IGSCC, the typical rock candy-like pattern. Meanwhile, local transgranular SCC (TGSCC) is also observed.

\section{Discussion}

Though the microstructure change in the $316 \mathrm{~L} \mathrm{HAZ}$ cannot be recognized by optical microscope, the HAZ has some microstructural differences from the base metal when studied by EBSD. And it is no doubt that it is the differences of the microstructure and residual strain between the HAZ and the base metal that determine their different SCC behavior.

\subsection{Changes of Microstructure and Residual Strain in the HAZ During Welding}

The EBSD verifies that the HAZ has higher residual strain, higher fraction of high-angle RGBs and lower fraction of CSL boundaries than the base metal (Figs. 8, 10, 11). All of these differences should be caused by the welding process.

The HAZ was not only affected by the thermal cycles during the welding process but also suffered high stress during the solidification of weld metal and the cooling of the weld joint as the different thermal expansion coefficients between weld metal and base metals [18]. Postweld heat treatment (PWHT) was only performed after the buttering process to release the residual stress, but no PWHT was applied on the weld joint after the welding process which also contributes to the high residual weld strain in the HAZ. According to other researches, the residual strain typically peaks at $>20 \%$ equivalent room temperature strain or cold working level [19]. The high micro-hardness in the HAZ is mainly related to the high residual strain and the high density of dislocations. According to previous studies, the relationship between micro-hardness $(H)$ and dislocation density $(\rho)$ can be presented as the following equation [20, 21]:

$H=H_{0}+a G b \rho^{1 / 2}$ 

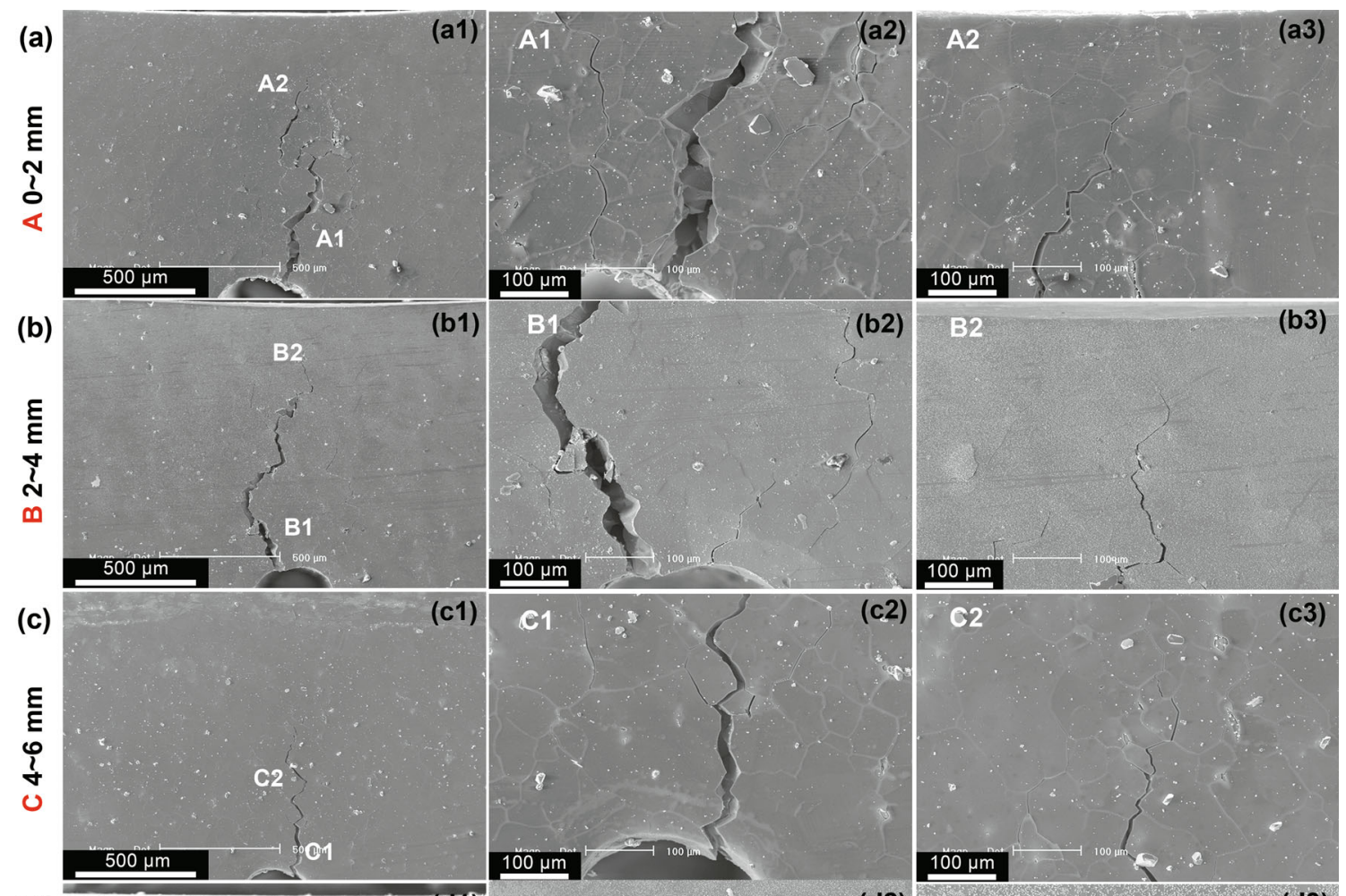

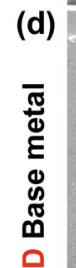

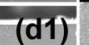

D1.

(d2)

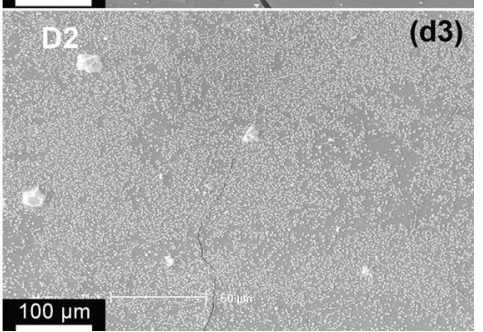

Fig. 12 a-d Surface morphologies of samples A-D after immersion test in the $3 \mathrm{wt} \% \mathrm{NaOH}$ solution at $325{ }^{\circ} \mathrm{C}$ for $378.5 \mathrm{~h}$. (al)-(dl) Surface morphology at low magnification, $(a 2)-(d 2)$ and $(a 3)-(d 3)$ higher magnification SEM figures for $(a 1)-(d 1)$

where $H_{0}$ is the hardness of the corresponding ideal material without any defects, $G$ is the shear modulus, and $b$ is the scalar value of Burgers vector. As $H_{0}$, $a, G$ and $b$ are the material's constants, $H$ increases as the incensement of $\rho$, and vice versa.

As mentioned before, the fast cooling rate of the weld metal and the short residence time under high temperature determine that the change of the fractions of different types of grain boundaries is mainly affected by the high stress (equals to cold work) but not the heat from the thermal cycle. Usually, with increasing the cold working level, the fractions of RGB and LAB increase, while the number of CSL decreases. For austenitic materials with FCC structure, the dislocation slip and twin deformation are two competing modes and often take place simultaneously to accommodate plastic deformation. The interactions between twin and dislocations are frequent and lead to the formation of randomly orientated refined crystals and would induce high fraction of RGBs [22]. Hou et al. [22] found that the CSL could be transformed into the RGB with high strain. LAB reveals the dislocations in materials, so higher number fraction of LAB means higher dislocations density in HAZ. Increasing the distance from the fusion boundary, the microstructure of $316 \mathrm{~L}$ will be less affected by the welding process and the resulted residual strain will decrease gradually.

By using non-destructive electrochemical test, Lima-Neto et al. [23] found no sensitization in the AISI $304 \mathrm{HAZ}$ when the welding energy was $0.7 \mathrm{~kJ} / \mathrm{mm}$. However, if the welding energy reached to $2.2 \mathrm{~kJ} / \mathrm{mm}$, the HAZ of 304 stainless steel was sensitized. The welding energy here used to fabricate this safe-end DMWJ was about $1.6 \mathrm{~kJ} / \mathrm{mm}$, and the $316 \mathrm{~L}$ HAZ was not sensitized as no "ditch" was found after metallographic etching according to ASTM A-262. 

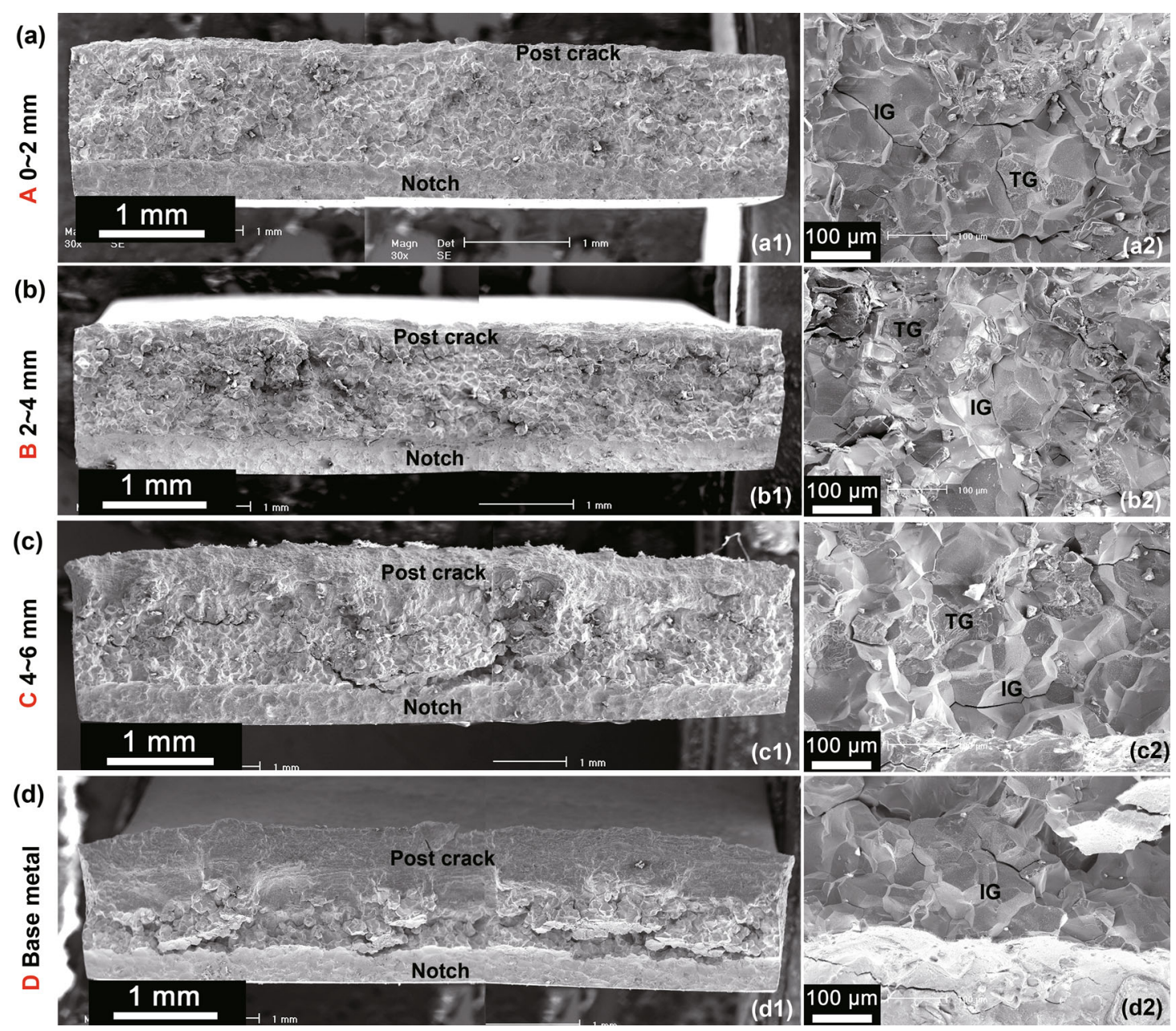

Fig. 13 SEM images of fracture surface of samples a-d after immersion test. (a2)-(d2) Higher magnification of the SCC zone in (a1)-(d1), respectively

\subsection{Effect of Microstructure on the SCC Behavior of 316L HAZ}

From the EBSD results of the samples after bending (Figs. 9, 10, 11), increasing the distance from the fusion boundary as the sequence from sample A to sample $\mathrm{D}$, the residual strain and the fraction of RGB decrease, while the fraction of CSL grain boundary increases. From SEM results of the side views (Fig. 12) and the fracture surfaces (Fig. 13) of the CBB samples after SCC experiment, it is summarized that the SCC resistance increases with increasing the distance from the fusion boundary. The different SCC resistance between different samples should be ascribed into the different microstructures, such as the GBCD and the residual strain.

It is well known that grain boundary diffusion, precipitation and corrosion at the grain boundaries are strongly dependent on the grain boundary structure [24]. As a result, the GBCD is believed to play a crucial role in the IGSCC
[25] and corrosion and this is the root cause why many attempts have been done to optimize it by grain boundary engineering (GBE) [26, 27]. Among these three types of grain boundaries (LAB, CSL and RGB), LAB and CSL boundaries are often considered to be the "special" boundaries due to their lower grain boundary energies and higher resistance to corrosion and IGSCC [28]. In particular, $\Sigma 3$ twin grain boundary is observed to possess the best SCC resistance as its energy is extremely low, typically about $1 / 50$ of a general boundary [29]. By using transmission electron microscopy, Kokawa et al. [24] found no precipitation at CSL boundary but $M_{23} \mathrm{C}_{6}$ precipitation at RGB in the 304 steel HAZ. The carbides at the RGB of the stainless steel are usually chromium carbides, and their formation always lead to a chromium-depleted region adjacent to the boundary which is favorable to intergranular corrosion and SCC [30]. Tan et al. [28] summarized the GBE effects on the structure materials of nuclear reactors and found that the number of cracked boundaries 
of 316L, 304, Alloy 690 and Alloy 600 decreased as increasing the fraction of CSL boundary. Taking the $15 \%$ strained $316 \mathrm{~L}$ as the example, the number of cracked boundaries decreased to be nearly $1 / 8$ when the fraction of CSL increased from $\sim 48$ to $\sim 82 \%[31,32]$. Zhang et al. [33] found the crack propagated along the RGB and no indication of cracking along CSL boundaries was found when studying the SCC growth rate of a cold-worked nuclear-grade $316 \mathrm{~L}$ stainless steel in simulated PWR primary water environment. Taking sample A as the example, as shown in Fig. 14, the crack path was marked out by dash-line circles in the GBCD figure. The cracks are also mainly along the RGB (white dash-line circle). However, there are also few cracks at the CSL boundaries (yellow dash-line circle). According to other researches, SCC can also be observed at CSL boundaries if these boundaries have large deviation degrees from ideal grain boundary structure [34].

However, the number fraction of RGB in sample A (0.482) is not much higher than that in sample D (0.402). As a result, even though GBCD significantly affects the SCC behavior, especially the crack path of different locations in 316L HAZ, it may not the main factor for SCC initiation. Actually, it is the residual strain lead to the different SCC behavior since the samples in HAZ have much higher residual strain than the one from the base metal after bending. The residual strain in sample $A$ is about 1.67 times higher than that in sample D. The effects of residual strain on SCC behavior can be elaborated in three aspects. First, high residual strain always leads to material strengthen or hardening. Higher micro-hardness of austenitic stainless steels is always detrimental to SCC resistance in high-temperature and high-pressure water as the stress at the crack tip is prone to be concentrated according to the Irwin-Orowan theory. So, higher residual strain always means higher SCC susceptibility. The cracked boundaries of $316 \mathrm{~L}$ with $25 \%$ strain are about three times higher than that of $316 \mathrm{~L}$ with $15 \%$ strain when they have the same fraction $(\sim 48 \%)$ of CSL boundaries. For Alloy 690, a fourfold rise in the cracked boundaries is found when the strain increased from 15 to $25 \%$ [31, 32]. No SCC will occur in the absence of stress (strain), regardless of the microstructure and/or its condition [35]. Then, the residual strain is found to be concentrated adjacent to the grain boundaries which will weaken the properties of the grain boundaries. The RGBs with higher residual strain will be much easier to oxidation and cracking, which means higher strain leads to higher SCC initiation rate. Third, as well known, high residual strain is advantageous to SCC growth rate.

As the SCC susceptibility in the 316L HAZ changes as the function of the distance from the fusion boundary, the SCC growth rate at different locations of HAZ will also be different. As a result, if the direct current potential drop method is used to study the SCC growth rate in the HAZ of austenitic materials in primary water, some special aspects should be noted. The parameters, such as the stress intensity factor, water chemistry, should not be changed if the
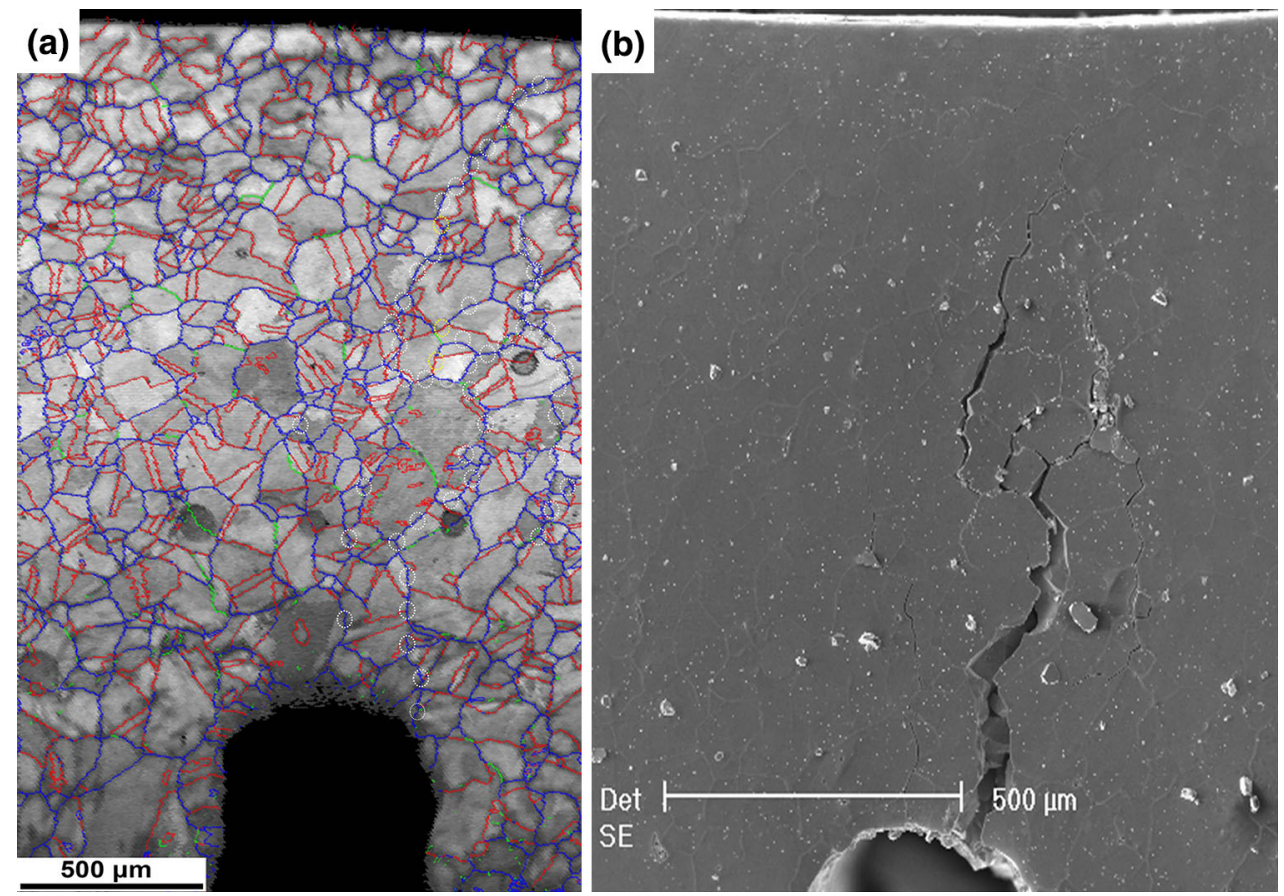

Fig. 14 Relationship between grain boundary character $\mathbf{a}$ and crack path $\mathbf{b}$ of sample A 
SCC growth path is perpendicular to the fusion boundary when studying the SCC growth rate of different parts of the $\mathrm{HAZ}$. If the effects of stress intensity factor or water chemistry on SCC growth rate of HAZ are studied, the notch or the pre-crack should be paralleled to the fusion boundary and the distance from the fusion boundary to the pre-crack should be given.

\section{Conclusions}

1. In $316 \mathrm{~L}$ HAZ, the residual strain, micro-hardness, fraction of random grain boundaries decrease and the fraction of CSL grain boundaries increases with increasing the distance from the fusion boundary.

2. The ratio of SCC area to the total fracture surface decreases with increasing the distance from the fusion boundary, that is, the closer to the fusion boundary, the lower the SCC resistance in 316L HAZ.

3. The different SCC behavior (including SCC initiation and propagation) between the four tested samples should be ascribed into the changes of the microstructure during welding process. The lower SCC resistance of the HAZ is mainly determined by the higher residual strain and the lower fraction of CSL grain boundaries.

Acknowledgments This work was financially supported by the National Natural Science Foundation of China (No. 51301183) and Science and Technology Commission of Shanghai Municipality under Grant No. 14DZ2250300, Shanghai, China.

\section{References}

[1] H.T. Wang, G.Z. Wang, F.Z. Xuan, C.J. Liu, S.T. Tu, Mater. Sci. Eng. A Struct. 568, 108 (2013)

[2] H. Ming, Z. Zhang, J. Wang, E.-H. Han, W. Ke, Mater. Charact. 97, 101 (2014)

[3] J. Hou, T. Shoji, Z.P. Lu, Q.J. Peng, J.Q. Wang, E.H. Han, W. Ke, J. Nucl. Mater. 397, 109 (2010)

[4] S. Wang, J. Ding, H. Ming, Z. Zhang, J. Wang, Mater. Charact. 100, 50 (2015)

[5] S. Suzuki, K. Takamori, K. Kumagayi, A. Sakashita, N. Yamashita, C. Shitara, Y. Okamura, E J. Adv. Maint. 1, 1 (2009)

[6] H. Ming, R. Zhu, Z. Zhang, J. Wang, E.-H. Han, W. Ke, M. Su, Mater. Sci. Eng. A Struct. 669, 279 (2016)
[7] Z.P. Lu, T. Shoji, Y. Takeda, Y. Ito, A. Kai, N. Tsuchiya, Corros. Sci. 50, 625 (2008)

[8] Z.P. Lu, T. Shoji, S. Yamazaki, K. Ogawa, Corros. Sci. 58, 211 (2012)

[9] Z.P. Lu, T. Shoji, H. Xue, F.J. Meng, C.Y. Fu, Y. Takeda, K. Negishi, J. Nucl. Mater. 423, 28 (2012)

[10] T.K. Yeh, G.R. Huang, M.Y. Wang, C.H. Tsai, Prog. Nucl. Energy 63, 7 (2013)

[11] M.M.D.A.M. Schvartzman, M.A.D. Quinan, W.R.D.C. Campos, L.I.L. Lima, Weld. J. 25, 15 (2011)

[12] H. Ming, Z. Zhang, J. Wang, R. Zhu, J. Ding, J. Wang, E.-H. Han, W. Ke, Appl. Surf. Sci. 337, 81 (2015)

[13] H.L. Ming, Z.M. Zhang, S.Y. Wang, J.Q. Wang, E.H. Han, W. Ke, Mater. Corros. 66, 869 (2015)

[14] W. Sagawa, T. Aoki, T. Itou, K. Enomoto, E. Hayashi, T. Ishikawa, Nucl. Eng. Des. 239, 655 (2009)

[15] K. Okamoto, A. Yoshinari, J. Kaneda, Y. Aono, T. Kato, Mater. Trans. 41, 806 (2000)

[16] Y.S. Lim, H.P. Kim, H.D. Cho, H.H. Lee, Mater. Charact. 60, 1496 (2009)

[17] G. Palumbo, K. Aust, E. Lehockey, U. Erb, P. Lin, Scr. Mater. 38, 1685 (1998)

[18] J. Hou, Q.J. Peng, Y. Takeda, J. Kuniya, T. Shoji, J.Q. Wang, E.H. Han, W. Ke, J. Mater. Sci. 45, 5332 (2010)

[19] P.L. Andresen, in Stress corrosion cracking of welded structures in light water reactors, International seminar on welding and non-destructive testing in nuclear power plants, Suzhou, China, 29 June 2009

[20] S.N. Geng, J.S. Sun, L.G. Guo, Mater. Des. 88, 1 (2015)

[21] J.P. Chu, J.M. Rigsbee, G. Banaś, H.E. Elsayed-Ali, Mater. Sci. Eng., A 260, 260 (1999)

[22] J. Hou, Q.J. Peng, Z.P. Lu, T. Shoji, J.Q. Wang, E.H. Han, W. Ke, Corros. Sci. 53, 1137 (2011)

[23] P. de Lima-Neto, J.P. Farias, L.F.G. Herculano, H.C. de Miranda, W.S. Araújo, J.-B. Jorcin, N. Pébère, Corros. Sci. 50, 1149 (2008)

[24] H. Kokawa, M. Shimada, Y.S. Sato, JOM 52, 34 (2000)

[25] E.M. Lehockey, A.M. Brennenstuhl, I. Thompson, Corros. Sci. 46, 2383 (2004)

[26] S. Xia, H. Li, T.G. Liu, B.X. Zhou, J. Nucl. Mater. 416, 303 (2011)

[27] C. Hu, S. Xia, H. Li, T. Liu, B. Zhou, W. Chen, N. Wang, Corros. Sci. 53, 1880 (2011)

[28] L. Tan, T.R. Allen, J.T. Busby, J. Nucl. Mater. 441, 661 (2013)

[29] V. Randle, The Role of the Coincidence Site Lattice in Grain Boundary Engineering (The Institute of Materials, London, 1996)

[30] M. Wang, L. Chen, X. Liu, X. Ma, Corros. Sci. 81, 117 (2014)

[31] E.A. West, G.S. Was, J. Nucl. Mater. 392, 264 (2009)

[32] S.M. Bruemmer, Mater. Res. Soc. Symp. Proc. 819, N2.2.1 (2004)

[33] L. Zhang, J. Wang, J. Nucl. Mater. 446, 15 (2014)

[34] Y. Pan, B.L. Adams, T. Olson, N. Panayotou, Acta Mater. 44, 4685 (1996)

[35] C.D. Lundin, Weld. J. 61, S58 (1982) 